\title{
FERENCZI E A EXPERIÊNCIA DA EINFÜHLUNG*
}

Nelson Ernesto Coelho Junior

Psicanalista, professor doutor, pesquisador e orientador dos cursos de graduação e pós-graduação do Instituto de Psicologia da USP.

RESUMO: Pretende-se acompanhar 0 desenvolvimento do pensamento psicanalítico de Sandor Ferenczi com relação ao tema da empatia (Einfühung). E ainda situar a contribuição ferencziana com relação às posições freudianas e frente ao contexto da atual valorização das experiências intersubjetivas nos debates clínicos e teóricos em psicanálise.

Palavras-chave: Ferenczi, empatia, intersubjetividade.

ABSTRACT: Ferenczi and the experience of Einfühlung. This article intends to follow the development of Sandor Ferenczi's psychoanalytical thought concerning the theme of empathy (Einfühlung). It also intends to situate the Ferenczian contribution to Freudian conceptions in the face of the context of the current valorization of intersubjective experiences in the clinical and theoretical debates in psychoanalysis.

Keywords: Ferenczi, empathy, intersubjectivity.

$\mathrm{N}^{\mathrm{s}}$ contato com um outro, posso me surpreender, ser traumatizado, ter experiências de estranhamento ou de familiaridade; posso "pensar" e "sentir" o outro a partir de minha imagem e semelhança ( projeções); posso mimetizá-lo na tentativa de ser como "ele"; posso sentir o peso e a atração de processos transferenciais e contratransferenciais; posso estar envolvido por identificações projetivas e contra-identifica-

\footnotetext{
*Texto apresentado no IX Simpósio de Pesquisa e Intercâmbio Científico da Associação Nacional de Pesquisa e Pós-Graduação em Psicologia (Anpepp), nas atividades do grupo de trabal ho Psicanálise Contemporânea: Convergências e Divergências, em Águas de Lindóia, São Paulo, agosto de 2002. Agradeço a leitura e os comentários dos membros do grupo de trabal ho e, especialmente, a Charles Lang e Patricia Getlinger, pela excelente leitura crítica do texto nessa versão final.
} 
ções projetivas; posso sofrer e produzir diferentes modalidades de processos identificatórios, posso, enfim, ser constituído pelo outro ou constituí-lo, ou vivenciar processos de mútua constituição. Essas diferentes formas de experiência têm sido foco de interesse de minhas pesquisas nos últimos oito anos. ${ }^{1}$

Algumas perguntas permanecem e insistem: Como posso conhecer 0 outro? Como posso entendêlo? Como conhecer um outro eu em sua radical alteridade sem "instituí-lo" seja por comparação, por analogia, seja por projeção ou introjeção, ou ainda por processos de fusão afetiva? É preciso considerar que estas últimas são todas formas que excluem a possibilidade do reconhecimento do outro em sua diferença, em geral reduzindo o outro a mim mesmo, ou concebendo sua existência à minha imagem e semelhança. Trata-se aqui de questões sobre formas de relação, comunicação e conhecimento entre um eu e um outro que podem ser tomadas como exercícios epistemológicos (de como conhecemos o que conhecemos), fortalecendo assim um interesse histórico e teórico, mas que deveriam implicar, principalmente, uma dimensão clínica e ética (que lugar 0 outro ocupa em minha vida, de que maneira me relaciono com ele, quais as conseqüências, para um outro, de minhas falas e ações). Questões, portanto, que entendo fundamentais para a clínica psicanalítica, mas que na maior parte dos autores centrais da história da psicanál ise não chegaram a merecer um tratamento mais elaborado. Pretendo mostrar, a seguir, as formulações de Sandor Ferenczi e o debate que estabeleceu com al gumas das posições freudianas menos reconhecidas sobre o tema. Procurarei, também, dar especial atenção às passagens dos textos em que Ferenczi valoriza as experiências psíquicas que remontam a conteúdos que nunca foram conscientes (ou pré-conscientes) anteriores, portanto, à compreensão verbal.

Vale lembrar, ainda nessas considerações introdutórias, que investigações filosóficas contemporâneas a Freud sobre o problema da empatia possuíam uma dimensão acima de tudo epistemológica, como por exemplo na obra de Husserl. ${ }^{2}$

\footnotetext{
${ }^{1}$ Em pesquisas anteriores, realizadas entre 1997 e 2002, foram criadas as bases para os aspectos centrais da investi gação mais específica que apresento aqui. Venho procurando estabelecer uma conceituação ao mesmo tempo metapsicológica e psicopatológica que viabilize novas pesquisas e concretize a afirmação de um campo de estudo que privilegie o diálogo crítico entre a filosofia e a psicanálise. Boa parte das idéias desenvolvidas nas pesquisas anteriores já está publicada (Cf. Coelho Junior, 1999a, 1999b, 2000a, 2000b, 2000c; Coelho Junior et al.,2000; Figueiredo \& Coelho Junior, 2000: Coelho Junior, 2002a, 2003a, 2003b; Coelho Junior \& Figueiredo, 2003).

2 Cf. Coelho Junior, 2003 b. No caso da filosofia fenomenológica, será apenas com o al uno de Husserl, o filósofo alemão Max Scheler, que a noção de intersubjetividade e a experiência empática poderão ser retiradas de uma dimensão exclusi vamente epistemológica e até questionadas, na medida que Scheler valoriza uma dimensão anterior à das distinções entre as experiências de dois indivíduos, fazendo predominar o plano da indistinção original e suas possibilidades expressivas.
} 
Ou seja, a pergunta por detrás do tema da empatia (e também do complexo campo da intersubjetividade) podia ser resumida em "Como é possível conhecer um outro?", ou até: "O outro existe, um outro existe, ou só possui existência a partir da consciência que possuo dele?" A filosofia do século XX viu estes temas receberem sucessivas vezes um tratamento ontológico (com H eidegger e MerleauPonty, por exemplo) e um tratamento ético (com Lévinas). Por outro lado, devese reconhecer que nos desenvolvimentos psicanalíticos realizados a partir das obras de Freud e Ferenczi, passando por trabal hos como os deW innicott e Kohut, até al cançar as contribuições mais recentes dos psicanalistas da escola relacional, a experiência e o conceito de intersubjetivdade e também o de empatia puderam assumir diferentes dimensões e conotações, à medida que seu uso pôde ser mais evidenciado, questionado e debatido. ${ }^{3}$

\section{FREUD E A NOÇÃO DE EINFÜHLUNG ${ }^{4}$}

A experiência do "sentir com" ( tradução literal do alemão Einfühlung) já aparecia designada pelos gregos em seu vocábulo empatheia, origem de nossa expressão 'empatia', indicando a enigmática possibilidade de estar dentro, estar presente, viver com e como o outro o seu pathos, paixão, sofrimento e doença. Indicando ora a possibilidade de projetar de modo imaginativo sua consciência e, assim, apreender o objeto contemplado, ora a capacidade de compreender os sentimentos e os pensamentos de um outro, colocando-se 'em seu lugar', a empatia possui múltiplas inserções na filosofia, na literatura e na história dos estudos estéticos e psicológicos.

Embora tenha passado despercebido para a maioria dos leitores, Freud fez em seus textos um uso significativo do vocábulo empatia (Einfühlung), como já bem demonstrou Pigman (1995) em seu artigo "Freud and the history of empathy". Desde o livro sobre os chistes (1905), encontramos no texto freudiano as marcas de sua familiaridade com a Einfühlung. No texto de 1913, "Sobre o início do tratamento", Freud considera central a experiência da Einfühlung para o trabalho terapêutico. Sugere que o estabelecimento de processos transferenciais está condicionado à capacidade do analista em adotar uma posição empática (curiosamente, na edição espanhola deste texto, a palavra alemã Einfühlung é traduzida por

\footnotetext{
${ }^{3} \mathrm{Cf}$. Coelho Junior \& Figueiredo, 2003, sobre os desdobramentos da noção e da experiência da intersubjetividade na filosofia, na psicologia e na psicanálise, a partir das seguintes dimensões: a) intersubjetividade interpessoal; b) intersubjetividade intrapsíquica; c) intersubjetividade traumática; d) o solo transubjetivo.

${ }^{4}$ Para um levantamento do uso da noção Einfühlung em autores que influenciaram Freud, como Theodor Lipps, por exemplo, e para um recenseamento do uso da noção na psicanálise contemporânea, remeto o leitor interessado à extensa bibliografia compilada por Pigman (1995).
} 
"actitud... de cariñoso interés y simpatia" e na tradução inglesa, por "standpoint... of sympathetic understanding"). ${ }^{5}$

Em carta datada de 4 de janeiro de $1928,{ }^{6}$ Freud apresenta a Ferenczi, criticamente, sua posição quanto à importância da empatia na clínica psicanalítica. Comentando um artigo que Ferenczi acaba de Ihe enviar, Freud reconhece que suas recomendações técnicas (textos de 1911-15) eram essencialmente negativas:

"Eu considerava que o mais importante a ser enfatizado era o que alguém não deveria fazer, demonstrar as tentações que trabalham contra a análise. Quase todas as coisas positivas que alguém poderia fazer eu deixava ao 'tato', que foi introduzido por você. Mas o que eu consegui com isso foi que os obedientes não se deram conta da elasticidade dessas dissuasões e se submeteram a elas como se fossem tabus. Isso precisaria ser revisto em algum momento, sem, evidentemente, revogar as obrigações." (FREUD \& FERENCZI, 2000, p.332)

Um pouco mais abaixo, Freud apresenta seus receios quanto aos usos que Ferenczi parece sugerir para o "tato" e para a capacidade de empatia (Einfühlung) que deve sustentá-lo: "Por mais verdadeiro que seja o que você tem a dizer sobre o 'tato', essa admissão parece-me ainda mais questionável nessa forma. Todos aqueles que não possuem tato verão nisso a justificativa de uma arbitrariedade, ou seja, de um fator subjetivo, ou seja, a influência de seus próprios complexos incontidos" (idem). Freud conclui suas recomendações e críticas de forma enérgica: "Regras sobre essas atitudes, evidentemente, não têm como ser feitas; a experiência e a normalidade do analista serão fatores decisivos. Mas deve-se, então, despojar o tato de seu caráter místico para os iniciantes" (idem). As recomendações de Freud não poderiam ser mais claras, revelando, do mesmo modo, seus mais profundos receios. Como se sabe, as prescrições e reprimendas de Freud não foram suficientes para inibir as incursões ferenczianas por um dos mais delicados campos da técnica e da teoria psicanalíticas.

Freud claramente reconhece o uso clínico da empatia, mas se isso poderia nos levar a pensar em uma atribuição de sentido de ordem mais afetiva ou emocional para essa noção (como o fará Ferenczi) , não é o que prevalece. No conjunto de sua obra, a empatia (Einfühlung) possui um sentido predominantemente cognitivo. A empatia revela, para Freud, processos que fazem com que possamos

5 Cf. Freud, 1913 "Zur Einleitung der Behandlung", in Studienausgabe, Ergánzungsband, p.199; Biblioteca Nueva, v. II, p.1672; Standard Edition, v. 12, p.139-140.

6 Thecorrespondence of Sigmund Freud and Sandor Ferenczi, v. 3, 1920-1933, carta 1.115, p. 331-333. Essa carta se inicia com uma referência histórica especialmente interessante para os brasileiros: “ 0 Correio de ontem trouxe duas especiais correspondências: um relato de São Paulo (Brazil), informando que um grupo de psicanálise acaba de se formar por lá...." 
compreender um outro ser humano através de uma capacidade cognitiva de nos colocarmos em seu lugar, consciente ou inconscientemente.

Sobretudo nas duas últimas décadas do século XX, o debate entre Freud e Ferenczi com relação às questões técnicas envolvidas no trabal ho analítico recebe o olhar interessado de vários psicanalistas ( como por exemplo, BARANDE, 1972; SCHNEIDER, 1988; BERGM AN, 1996; GIAM PIERI-DEUTSCH, 1996; HOFFER, 1996). Para H offer (1996), por exemplo, as proposições freudianas revelam uma concepção assimétrica e autoritária da relação analítica, em oposição às concepções dos últimos textos de Ferenczi, que revelavam um autor inclinado a privilegiar a mutualidade, a igual dade e a simetria entre analista e paciente. A despeito das conseqüências sugeridas por Hoffer, seguramente um pouco caricatas (a posição patriarcal, intelectualista e autoritária de Freud e o movimento fraternal, afetivo e igualitário de Ferenczi gerando modelos distintos para o desenvolvimento da técnica analítica contemporânea), não resta dúvida que a tensão estabelecida entre as posições conflitantes de Freud e Ferenczi nos obrigam a uma retomada histórica e conceitual para não nos vermos aprisionados em defesas simplistas e emocionalmente comprometidas com esta ou aquela forma de trabalho clínico.

As idéias que apresentarei a seguir revelam algumas das diferentes concepções sobre aspectos intersubjetivos e empáticos no contexto analítico, desenvolvidas por Sandor Ferenczi entre os anos de 1918 e 1932. Procurarei acompanhar os textos de Ferenczi do modo o mais próximo possível, citando-o sempre que necessário, para manter as intenções de um artigo histórico-crítico e para, ao mesmo tempo, desvelar a proposição ética da concepção clínica de Ferenczi.

\section{FERENCZI, A EMPATIA E A INTERSUBJ ETIVIDADE: QUESTÕES PARA ALÉM DA TÉCNICA}

Muito já se escreveu sobre as inovações técnicas introduzidas por Ferenczi no campo da psicanálise. 0 que ainda pode causar surpresa para muitos de nós, familiarizados com os textos iniciais de Freud sobre a técnica psicanalítica ( 1912 1914), é encontrar essas inovações nos textos de Ferenczi publicados não muito tempo depois e em plena convivência com o que pode ser considerada a ortodoxia psicanalítica. Embora procurasse se manter bastante próximo deFreud, Ferenczi acabava constantemente revelando idéias e concepções técnicas que aos poucos passaram a afastá-lo do caminho preconizado por Freud.

Assim como ocorrerá em outros textos sobre o tema da técnica, em uma conferência proferida em dezembro de 1918 em Budapeste, Ferenczi começa afirmando: "Todo o método psicanalítico apoia-se na 'regra fundamental' formulada por Freud, ou seja, a obrigação para o paciente de comunicar tudo o que Ihe vem ao espírito no decorrer da sessão de análise" (FERENCZI, 1919/ 1992, 
p.357) . A fidelidade não é apenas aparente: “Não se deve, sob nenhum pretexto, tolerar qualquer exceção a essa regra e é imprescindível esclarecer, sem indulgência, tudo 0 que o paciente, seja qual for a razão evocada, procura subtrair à comunicação" (FERENCZI, 1919/ 1992, p.357). Até aí nada de novo. Na seqüência do texto, ele tratará da forma como o analista deve responder a perguntas formuladas pelos pacientes, do papel do 'por exemplo' na análise e, o que mais nos interessa, do 'domínio da contratransferência'. Ferenczi aponta que o psicanalista "não tem mais o direito de ser, à sua moda, afável e compassivo ou rude e grosseiro na expectativa de que o psiquismo do paciente se adapte ao caráter do médico" (FEREN CZI, 1919/ 1992, p.365). A forma de apresentar essa prescrição, no entanto, já revela o ol har atento de Ferenczi para as sutilezas da percepção e as emoções vividas pelo analista em seu trabalho:

"Mas sendo o médico, não obstante, um ser humano e, como tal, suscetível de humores, simpatias e antipatias e também de ímpetos pulsionais - sem uma tal sensibilidade não poderia mesmo compreender as lutas psíquicas do paciente - é obrigado, ao longo da análise, a realizar uma dupla tarefa: deve por um lado observar o paciente, examinar suas falas, construir seu inconsciente a partir de suas proposições e de seu comportamento; por outro lado, deve controlar constantemente sua própria atitude a respeito do paciente e, se necessário, retificá-la, ou seja, dominar a contratransferência." (Freud) (FERENCZI, 1919/ 1992, p.365)

Ferenczi, acompanhando Freud, defende que o analista domine a contratransferência mas, desde então, a porta estará aberta para a investigação do complexo campo das experiências intersubjetivas na situação analítica, justamente porque Ferenczi explicita que 0 analista tem como instrumento fundamental de compreensão da experiência psíquica do paciente uma "sensibilidade". 0 texto termina com o seguinte parágrafo:

"A terapêutica analítica cria, portanto, para o médico, exigências que parecem contradizer-se radicalmente. Pede-lhe que dê livre curso às suas associações e às suas fantasias, que deixe falar o seu próprio inconsciente; Freud nos ensinou, com efeito, ser essa a única manei ra de aprendermos intuitivamente as manifestações do inconsciente, dissimuladas no conteúdo manifesto das proposições e dos comportamentos do paciente. Por outro lado, o médico deve submeter a um exame metódico o material fornecido, tanto pelo paciente, quanto por ele próprio, e só esse trabalho intelectual deve guiálo, em seguida, em suas fal as e em suas ações. Com o tempo, ele aprenderá a interromper esse estado permissivo em face de certos sinais automáticos, oriundos do pré-consciente, substituindo-o pela atitude crítica. Entretanto, essa oscilação permanente entre o livre jogo da imaginação e o exame crítico exige do psicanalista o que 
não é exigido em nenhum outro domínio da terapêutica: uma liberdade e uma mobilidade dos investimentos psíquicos, isentos de toda inibição." (FERENCZI, 1919/ 1992, p.367)

Seria difícil colocar de forma mais elegante o que é exigido do analista em seu trabalho. Definir o trabalho do analista como uma oscilação permanente entre o livre jogo da imaginação e o exame crítico, em 1919, é, sem dúvida alguma, um passo à frente não apenas em termos técnicos, mas também quanto à concepção das formas de comunicação entre os sujeitos que constituem o campo analítico.

No texto de 1921, “Prolongamentos da'técnica ativa' em psicanálise”, Ferenczi apresenta com todo cuidado as razões para a introdução de variações na técnica analítica, deixando claro que essas mudanças limitam-se a poucos casos, como por exemplo, certas formas de histeria de conversão. Percebe-se ao longo do texto sua cautela para não distanciar-se das idéias de Freud, contendo ao máximo seus impulsos de mudança e, por que não, de ação. Mas, como reconhece Barande (1972), apesar de todos os esforços de Ferenczi em apontar as restrições que precisavam ser consideradas com relação à técnica ativa, "a constatação do desmedido continuava a se aplicar à'atividade'" (p.171). Em seu esforço para clarear o campo em que a técnica ativa se justificaria, Ferenczi sugere ser possível reconhecer conteúdos psíquicos inconscientemente patogênicos, de períodos muito precoces e que nunca foram conscientes (ou pré-conscientes), e que teriam sua origem no que ele denomina “ período dos'gestos incoordenados' ou dos'gestos mágicos', portanto da época anterior à compreensão verbal" (FERENCZI, 1921/ 1993, p.125). Para Ferenczi, esses conteúdos não têm como "ser rememorados mas somente revividos no sentido da repetição freudiana" (FERENCZI, 1921/ 1993, p.125). Desta forma, procura estabelecer as características da técnica ativa, que para ele desempenharia apenas "o papel do agente provocador, cujas injunções e interdições favorecem repetições que cumpre em seguida interpretar ou reconstituir nas lembranças" (FERENCZI, 1921/ 1993, p.125). E, citando Freud, lembra que é "uma vitória da terapêutica quando se consegue libertar pela via da lembrança 0 que o paciente queria descarregar pela ação". Com isso, conclui o texto afirmando que "a técnica ativa não tem outra finalidade senão revelar, pela ação, certas tendências ainda latentes para a repetição e ajudar assim a terapêutica a obter esse triunfo um pouco mais depressa do que antes" (FERENCZI, 1921/ 1993, p.125).

Conhecendo-se as discussões atuais em torno dos enactments e acting outs, ${ }^{7}$ na esteira dos desenvolvimentos técnicos " pós- identificação projetiva" , não é mui-

7 Remeto o leitor interessado ao conjunto de artigos sobre o tema editados por ELLMAN \& MOSKOWITZ, 1998, sob o título Enactment:Toward a new Approach to theTherapeutic Relationship. 
to difícil reconhecer Ferenczi, como já o fezAndré Green, como o pai de grande parte da psicanálise contemporânea. A atenção para experiências psíquicas que remontam a conteúdos que nunca foram conscientes (ou pré-conscientes), anteriores à compreensão verbal, fazem de Ferenczi o patrono de discussões técnicas que até hoje nos incitam e fazem pensar. Para ele, em alguns momentos, a atitude de provocar uma ação era a al avanca necessária para que pudesse haver posterior elaboração, lado a lado com uma atitude de estreita sintonia com a experiência emocional do paciente para melhor equalizar temporalmente tais intervenções que favorecessem 0 andamento da análise. Mas, cuidadoso, Ferenczi sempre insistiu que "nas mãos de um novato, a atividade poderia facilmente conduzir a um retorno aos procedimentos pré-psicanalíticos da sugestão e das medidas autoritárias" (FERENCZI, 1926/ 1993 p.365). E, referindo-se a enganos e problemas enfrentados no uso da técnica ativa, reafirma que "as nossas instruções ativas não devem ser, segundo a expressão de um colega a quem analisei, de uma intransigência estrita, mas de uma flexibilidade elástica" (FERENCZI, 1926/ 1993, p.368).

Por fim, ainda nesse texto de 1926, "Contra-indicações da técnica ativa", Ferenczi é acometido de um furor filosófico e desenvolve argumentação diretamente ligada ao tema da empatia e da intersubjetividade, que embora muito extensa, merece ser citada na íntegra:

“...na realidade nunca se pode chegar à 'convicção' pela via da inteligência, que é uma função do ego. 0 solipsismo constitui aúltima palavra, logicamente irrefutável, da pura intelectualidade do ego sobre a relação com outros indivíduos; segundo essa teoria, nunca se pode colocar no mesmo plano a realidade dos outros seres humanos ou do mundo externo eas próprias experiências pessoais; pode-se somente considerar os outros como fantasias mais ou menos animadas ou projeções. Portanto, quando Freud atribuiu ao inconsciente essa mesma natureza psíquica que se experimenta como qualidade do próprio ego, ele deu um passo na direção do positivismo que, do ponto de vista lógico, é presumível mas não poderia ser demonstrado. Não hesito em assimilar essa identificação e as identificações que sabemos ser a condição das transferências libidinais. Ela conduz finalmente a uma espécie de personificação ou de concepção animista de todo o mundo circundante. Considerando sob o ângulo lógico-intelectual, tudo isso é de natureza'transcendente'. O ra, nós somos levados a substituir esse termo de ressonância mística por expressões como 'transferência' ou 'amor', e a afirmar afoitamente que o conhecimento de uma parte da realidade, talvez a mais importante, não pode converter-se numa convicção pela via intelectual mas somente na medida em que ela estiver em conformidade com a vivência afetiva. Apresso-me a acrescentar, a fim de não deixar triunfar por mais tempo os adversários do conhecimento e da ciência, que o conhecimento da importância do elemento emocional constitui em si mesmo um conhecimento e que, portanto, nada temos a temer quanto ao futuro da 
ciência. Sinto-me pessoalmente convertido ao positivismo freudiano e prefiro ver em vocês, que estão sentados diante de mim e me escutam, não representações de meu ego mas seres reais com os quais posso identificar-me. Sou incapaz de demonstrá-lo logicamentemas se, apesar de tudo, estou convencido disso, devo-o a um fator emocional - se assim quiserem - à transferência." (FERENCZI, 1926/ 1993, p.374-375)

Poucos fenomenólogos ou adeptos da contemporânea psicanálise relacional teriam sido capazes de escrever passagem tão convincente em defesa da experiência intersubjetiva. De qualquer forma, é preciso destacar aqui a definição que Ferenczi nos dá do fenômeno transferencial, ou seja, um fator emocional. Recusa o primado da comunicação de ego a ego, a partir de representações, e afirma 0 primado de processos identificatórios apoiados em um fator emocional. Afirma, com todas as letras, que conviçcões, em termos da experiência analítica, não são conquistas intel ectuais, mas sim conhecimentos que devem ser atri buídos à concordância entre uma parte da realidade e a vivência afetiva. Está preparado 0 terreno para as últimas incursões de Ferenczi pelo plano da técnica e da ética psicanalíticas.

Em texto de 1928, "Elasticidade da técnica psicanalítica", Ferenczi introduz um conceito que já havia sido ponto de discussão em sua correspondência com Freud: o tato psicológico. Escreve Ferenczi: “Mas o que é o tato? A resposta a esta pergunta não nos é difícil. 0 tato, éa faculdade de'sentir com' (Einfühlung)" (FERENCZI, 1928/ 1992, p.27). Ferenczi desenvolve seu argumento a partir do que denomina "a ajuda de nosso saber", que ele diz ser retirado da investigação de numerosos psiquismos, mas em particular de análises do funcionamento de seu próprio 'eu'. Com isso ele afirma que é possível trazer à tona, em uma análise, "as associações possíveis ou prováveis do paciente, que ele ainda não percebe e poderemos - não tendo como ele, de lutar com resistências - adivinhar não só seus pensamentos retidos mas também as tendências que Ihe são inconscientes" (FEREN CZI, 1928/ 1992, p.27). É claro que nossos ouvidos, bem como os de muitos dos psicanalistas contemporâneos de Ferenczi, não podem deixar de estranhar a presença do verbo 'adivinhar', usado por um analista no tocante às tendências inconscientes de seus pacientes. Ferenczi prossegue: "Devo sublinhar uma vez mais que só uma verdadeira posição de "sentir com" (Einfühlung) pode ajudar-nos; os pacientes perspicazes não tardam em desmascarar toda pose fabricada" (FERENCZI, 1928/ 1992, p.32). Mas o sentir com não deve ser considerado 0 único instrumento que 0 analista possui para levar adiante uma análise. Como bem aponta Ferenczi, antecipando muitos dos textos técnicos da psicanálise contemporânea: “De fato, quase poderíamos falar de uma oscilação perpétua entre 'sentir com' (Einfühlung), auto-observação e atividade de julgamento" (FERENCZI, 1928/ 1992, p.32-33). 
Aqui aparece toda a competência clínica e teórica desenvolvida por Ferenczi. Afinal, não se trata de endeusar uma capacidade de empatia, que nada produziria sozinha em um trabalho analítico. Mas tampouco e trata do oposto: Ferenczi afirma que a atividade de julgamento "anuncia-se, de tempos em tempos, de um modo inteiramente espontâneo, sob a forma de sinal que, naturalmente, só se avalia primeiro como tal; é somente com base num material justificativo suplementar que se pode, enfim, decidir uma interpretação" (FERENCZI, 1928/ 1992, p.32-33). E, antecipando-se criticamente a uma das mais cristalizadas características de alguns modelos pós-freudianos da técnica psicanalítica, Ferenczi reafirma que "ser parcimonioso nas interpretações, em geral, nada dizer de supérfluo, é uma das regras mais importantes da análise; o fanatismo da interpretação faz parte das doenças de infância do analista." (FEREN CZI, 1928/ 1992, p.33)

Por outro lado, para não deixar dúvidas de que realmente procurava seguir as prescrições de Freud e de que, de forma nenhuma poderia ser julgado como um ingênuo voluntarioso, Ferenczi, quase no final do texto afirma: "a única base confiável para uma boa técnica analítica é a análise terminada do analista. É evidente que num analista bem analisado, os processos de 'sentir com' (Eifühlung) e de avaliação, exigidos por mim, não se desenrolarão no inconsciente mas no nível pré-consciente" (FERENCZI, 1928/ 1992, p.36). Ou seja, antes de valorizar a Eifühlung como a marca do inefável, que teria sua origem nas profundidades de um insondável inconsciente, Ferenczi criteriosamente situa a possibilidade empática de um analista (diríamos 'bem analisado') no nível pré-consciente. Entendo que, assim, Ferenczi acaba por fortalecer uma compreensão dos processos empáti cos a partir de relações entre percepções e afetos que não pertencem nem ao plano das representações conscientes nem ao plano das representações 'localizadas' no sistema inconsciente, propriamente dito.

Nos textos do Diário clínico encontraremos, ainda, muitas afirmações decisivas para nosso tema. Nas notas de 17 de janeiro de 1932, que receberam o título "A análise mútua e limites de sua aplicação", Ferenczi relata questões técnicas que acabam por implicar em algumas confissões do analista para o paciente sobre seus estados afetivos e sobre certas atitudes transferenciais e contratransferenciais e, ao final, escreve:

"Agora, al go de 'metafísico'. Muitos pacientes têm a sensação de que uma vez atingida essa espécie de paz mútua, a libido, liberta de todos os conflitos, terá, sem outro esforço intelectual ou de explicação, um efeito 'curativo'. Eles me pedem para não pensar demais, mas estar simplesmente presente; para que eu não fale, que não faça qual quer esforço; de fato, eu poderia até dormir. Os dois inconscientes ajudar-se-iam mutuamente dessa maneira..." (FERENCZI, 1990 p.43) 
É inevitável que uma afirmação como essa ainda incomode o mais heterodoxo dos analistas, mesmo passados mais de 70 anos. As propostas da análise mútua de Ferenczi requerem um cuidado interpretativo adicional e talvez precisem ser reconhecidas como o caso mais extremo do uso da experiência empática em um contexto psicanalítico. Resta saber se ainda é possível fal ar em psicanálise nesses casos. Retomemos, por fim, uma última afirmação de Ferenczi sobre o tema. $\mathrm{Na}$ nota de 19 de janeiro de 1932, "Continuação da análise mútua", reencontramos Ferenczi absolutamente envolvido com as tramas intersubjetivas e empáticas da experiência analítica: “É como se duas metades da alma se completassem para formar uma unidade. Os sentimentos do analista entrelaçam-se com as idéias do analisado e as idéias do analista (imagens de representações) com os sentimentos do analisado" (FERENCZI, 1990, p.45).

A despeito da opinião que cada um de nós pode ter hoje em dia sobre essas posições de Ferenczi, não há como recusar que seu trabal ho amplia o horizonte ético implicado no trabalho analítico. Postular que sentimentos e idéias de analista e paciente podem entrelaçar-se e que o outro à minha frente não é "uma representação de meu ego", mas um ser real com quem posso me identificar, explicita um reconhecimento do outro em termos éticos, em uma amplitude até então pouco valorizada nos textos psicanalíticos.

Muitas outras passagens poderiam ser evocadas para fortalecer os argumentos já apresentados, mas entendo que essa seqüência é mais do que suficiente para mostrar um caminho clínico que exigiu que Ferenczi abrisse as portas, definitivamente, para uma compreensão da experiência analítica como al go muito além do uso de uma técnica para a análise e investigação do psiquismo de um paciente focalizado como objeto, restrita ao âmbito de one person psychology. ${ }^{8}$ Mesmo sem chegarmos ao extremo de seus experimentos de anál ise mútua, temos que reconhecer que Ferenczi, entre os analistas da primeira geração, foi o mais sensível à dimensão da two person psychology e dos aspectos intersubjetivos e empáticos presentes em uma análise. A ele devemos grande parte das inovações técnicas que permitiram à psicanálise um campo de atuação para além do trabalho clássico com pacientes reconhecidos como neuróticos. Mas isso a história da psicanálise já pôde reconhecer, apesar dos esforços persistentes entre os anos 1940 e 60 para emudecer o legado ferencziano.

Recebido em 10/ 7/ 2003. Aprovado em 28/ 11/ 2003.

${ }^{8}$ Cf. Ghent, 1989, e Gill, 1993. Por one person psychology entende-se a tradição que concebe o analista no lugar do observador, tendo como objeto de estudo o psiquismo de um paciente; por two person psychology, a prática que inclui a experiência subjetiva do analista como parte integrante do processo de análise. 


\section{REFERÊNCIAS}

BARANDE, I. (1972) Sandor Ferenci. Paris: Payot.

BERGM AN, M. S. (1996) "TheTragic Encounter between Freud and Ferenczi and its Impact on the History of Psychoanalysis", in RUDNYTSKY, P.L., BÓKAY,A ., GIAM PIERI-DEUTSCH, P.( 1996) Ferenci'sTurn in Psychoanalysis. New York: New York University Press.

COELHO JUNIOR, N.E (1999a) “Inconsciente e percepção na psicanálise freudiana", Psicologia - USP, 10, (1), São Paulo, p.25-54.

(1999b) "Usos da percepção na psicanálise contemporânea"

Percurso- Revista de Psicanálise, ano XII, n. 23, 1999, p.97-106.

(2000a) "Liberdade e Determinismo: um questionamento ético direcionado à psicanálise" RevistaTempo Psicanalítico, Rio de Janeiro, $n$. 32,2000, p.25-34.

(2000b) "Percepções e destinos da percepção na psicanálise freudiana", in: Psicanálisee universidade temas contemporâneos, Marzagão, L.R., Afonso, M.L.M. e Ribeiro, P. de C., Belo Horizonte: A.S. Passos Editora, p.83-98.

(2000c) “Merleau-Ponty e o primado da percepção: diálogos com a psicanálise", Revista de Psicologia - Universidade Federal do Ceará, v.15/ 16, anos 1997-1998, p.11-26.

. (2002) “Intersubjetividade: conceito e experiência em psicanálise", Psicologia Clínica. PU C-RIO, v.14, n. 1, p.61-74. Rio de Janeiro: Companhia de Freud Editora.

. (2003a) “Douleur et souffrance dans les expériences d'isolement personnel", in: GRANGER, B. et CHARBON NEAU, G. Phénoménologie des Sentiments Corporels - I. Douleur, souffrance, dépression. Paris: Le Cercle Herméneutique, p.143-148.

. (2003b) "Da intersubjetividade à intercorporei dade: contribuições da filosofia fenomenológica ao estudo psicológico da alteridade" Psicologia USP, v. 14, n.1, p.185-209.

COELHO JUNIOR, N. E e FIGUEIREDO, L.C. (2003) “Patterns of Intersubjectivity in the constitution of subjectivity: Dimensions of otherness." Culture and Psychology, v.9, n. 3, September, 2003. London: Sage Publications, p.193-208.

COELHO JUNIOR, N E., PACHECO FILHO, R.A. e ROSA, M.D. (orgs.) (2000) Ciência, representaç̧ão e realidade na psi canálise contemporânea, São Paulo: Educ/ Casa do Psicólogo, 289 p.

ELLMAN, S. J. \& MOSKOWITZ, M. (eds.) (1998) Enactment- toward a new approach to the therapeutic relationship. Northvale: Jason Aronson.

FERENCZI, S. (1919/ 1992) "A técnica psicanalítica", in Sándor Ferencz. Obras completas, v. II. São Paulo: Martins Fontes. (1921/ 1993) “Prolongamentos da'técnica ativa' em psicanálise", in Sándor Ferenci. Obras completas, v. III. São Paulo: Martins Fontes. . (1926/ 1993) "Contra-indicações da técnica ativa", in Sándor Ferenczi. Obras completas, v. III. São Paulo: Martins Fontes. . (1928/ 1992) "A elasticidade da técnica psicanalítica", in Sándor Ferencz. Obras completas, v. IV. São Paulo: Martins Fontes. 
(1990) Diário clínico . São Paulo: Martins Fontes.

FIGUEIREDO, L.C. e COELHO JU NIOR, N. (2000) Ética etécnica em psicanálise. São Paulo, Escuta.

FREUD, S. (1913/ 1975) "Zur Einleitung der Behandlung”, Studienausgabe, Ergänzungsband, Frankfurt am Mein: S. Fischer Verlag.

. (1913/1981) "La Iniciación del tratamiento", in Obras completas de Sigmund Freud. v. II. Madrid: Biblioteca Nueva.

. (1913/ 1958) "On beginning the treatment", in Standard Edition of the Complete Psychological W orks, v. 12. London: Hogarth Press.

FREUD, S. \& FEREN CZI, S. (2000) The Correspondence of Sigmund Freud and Sándor Ferenczi, volume 3, 1920-1933. Edited by Ernst Falzeder and Eva Brabant.Combridge: Harvard University Press.

GHENT, E. (1989) "Credo: The dialectics of one-person and two-person psychologies". Contemporary Psychoanalysis, 25, p.169-211.

GIAMPIERI- DEUTSCH, P.(1996) "The Influence of Ferenczi's Ideas on Contemporary Standard Technique", in RUDNYTSKY, P.L., BÓKAY, A ., GIAM PIERI-DEU TSCH, P. (1996) Ferenczi'sTurn in Psychoanalysis. N ew York: New York Univerity Press.

GILL, M. M. ( 1983) “The point of view of psychoanalysis: Energy discharge or person? Psychoanalytical Contemporary Thought, 6, p.523-552.

GREEN, A. (2000) "The Intrapychic and intersubjective in psychoanalysis", The Psychoanalytic Quarterly, v. LXIX, n. 1, 2000, p.1-39.

HOFFER, A . (1996) "Asymetry and mutuality in the analytic relationship: contemporary lessons from Freud-Ferenczi dialogue", in RUDNYTSKY, P.L., BÓKAY, A., GIAM PIERI-DEUTSCH, P.(1996) Ferenczi's Turn in Psychoanalysis. New York: New York Univerity Press.

PIGMAN, G.W. (1995) "Freud and the history of Empathy", Thel nternational Journal of Psycho-Analysis, v. 76, p.237-256.

SCHNEIDER, M. (1988) LeTrauma et la filiation paradoxale. Paris: Éditions Ramsay.

$\mathrm{N}$ es son Ernesto Coelho Junior

Alameda Lorena, 1.359/ 82

01424-001 São Paulo SP

Tel/ fax (11) 3288-8202

ncoelho@usp.br 